\title{
Rare Case of Diffuse Spinal Arachnoiditis Following a Complicated Vertebral Artery Dissection
}

\author{
Elias Atallah, MD \\ Thomas Jefferson University \\ Sophia Dang \\ Thomas Jefferson University \\ Sage Rahm \\ Thomas Jefferson University \\ Nohra Chalouhi, MD \\ Thomas Jefferson University \\ Stavropoula Tjoumakaris MD \\ Thomas Jefferson University \\ Follow this and additional works at: https://jdc.jefferson.edu/neurosurgeryposters

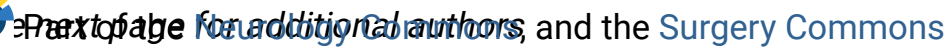 \\ Let us know how access to this document benefits you
}

\section{Recommended Citation}

Atallah, MD, Elias; Dang, Sophia; Rahm, Sage; Chalouhi, MD, Nohra; Tjoumakaris, Stavropoula MD; Rosenwasswer MD, Robert H.; and Jabbour, Pascal MD, "Rare Case of Diffuse Spinal Arachnoiditis Following a Complicated Vertebral Artery Dissection" (2018). Department of Neurosurgery Posters. 10. https://jdc.jefferson.edu/neurosurgeryposters/10

This Article is brought to you for free and open access by the Jefferson Digital Commons. The Jefferson Digital Commons is a service of Thomas Jefferson University's Center for Teaching and Learning (CTL). The Commons is a showcase for Jefferson books and journals, peer-reviewed scholarly publications, unique historical collections from the University archives, and teaching tools. The Jefferson Digital Commons allows researchers and interested readers anywhere in the world to learn about and keep up to date with Jefferson scholarship. This article has been accepted for inclusion in Department of Neurosurgery Posters by an authorized administrator of the Jefferson Digital Commons. For more information, please contact: JeffersonDigitalCommons@jefferson.edu. 


\section{Authors}

Elias Atallah, MD; Sophia Dang; Sage Rahm; Nohra Chalouhi, MD; Stavropoula Tjoumakaris MD; Robert H. Rosenwasswer MD; and Pascal Jabbour MD 


\section{Jefferson

\begin{abstract}
Introduction
Spinal arachnoiditis (SA) is an extremely rare and delayed complication of intracranial subarachnoid hemorrhage (SAH). SA is an inflammatory process leading to chronic fibrosis of the spinal cord. Possible pathophysiology is a two-staged disease of initial inflammatory (ie.SA). The clinical coutse can be complicated and is the cause of major morbidity.

- 25 case reports since first described by Nelson in 1943. Ours is the 26 th case reported. Majority of cases occur in females (86\%) between ages of 22 and 69 years old. ${ }^{\circ}$ High predilection of SA at level of thoracic spine ${ }^{8}$

18/25 had SAH after aneurysm rupture.

16/18 involved posterior circulation arteries: $13 \mathrm{PICA}^{*}, 2 \mathrm{PCom}^{*}$

Our case involves the vertebral artery (VA)

SA can arise anytime from 1 month to 12 years after SAH.

- SA complications include arachnoid cysts ${ }^{1-4}$, syringomyelia2,5,6, and spinal cord compression (e.g. cauda equina syndrome) ${ }^{7}$

- Little is still known about underlying inflammatory pathogenesis and clinical pattern.

PICA = posterior inferior cerebellar a atren, PCom = posterior communicating artery, VA = vertebral artery
\end{abstract}

\section{Clinical Case Report}

DAY 0-1

- 47-year-old female complains of having the "worst headache" of her life and a grade 3 SAH.

- Past medical history: benign paroxysmal positional vertigo (BPPV)

- Diffuse Subtraction Angiography (DSA):

Ruptured dissection/dissecting fusiform aneurysm of V4 segment of left VA

Intact $1.7 \times 1 \mathrm{~mm}$ aneurysm at proximal A1 segment of left ACA

- CT scan: diffuse SAH in the basal cisterns and posterior fossa extending through the

- VA dissection was treated with flow diversion using pipeline embolization (PE)
foramen magnum.

TWO WEEKS LATER

- Patient ruptured her A1 ACA aneurysm and re-ruptured/re-bled from her VA dissection. - A1 ACA aneurysm was treated with PE. VA dissection was re-treated with second PE. - Hospital course complications:

Polymicrobial ventriculitis - treated with PICC-line broad spectrum antibiotics.

SEVERAL MONTHS LATER

- New onset of paraparesis and left-sided weakness, dizziness, positional nausea, and gait

ataxia

- MRI (fig. A, B) showed thecal dural thickening from the cervicomedullary junction $\rightarrow \mathrm{C} 4$ and

from T5 extending circumferentially $\rightarrow$ sacrum.

- MRI (fig. A) also showed various degrees of cord compression along inferior surface of

cerebellum, anteriorly within cervical and thoracic canals, and T4-T6 syrinx with diffuse spinal

edema.

- Ventricular shunt and decompression surgery of T5-T7 were performed.

LATEST FOLLOW-UP

- Patient had full-strength with moderate gait instability and was weaning off of her

thoracolumbosacral orthosis back brace. She currently ambulates with a cane.

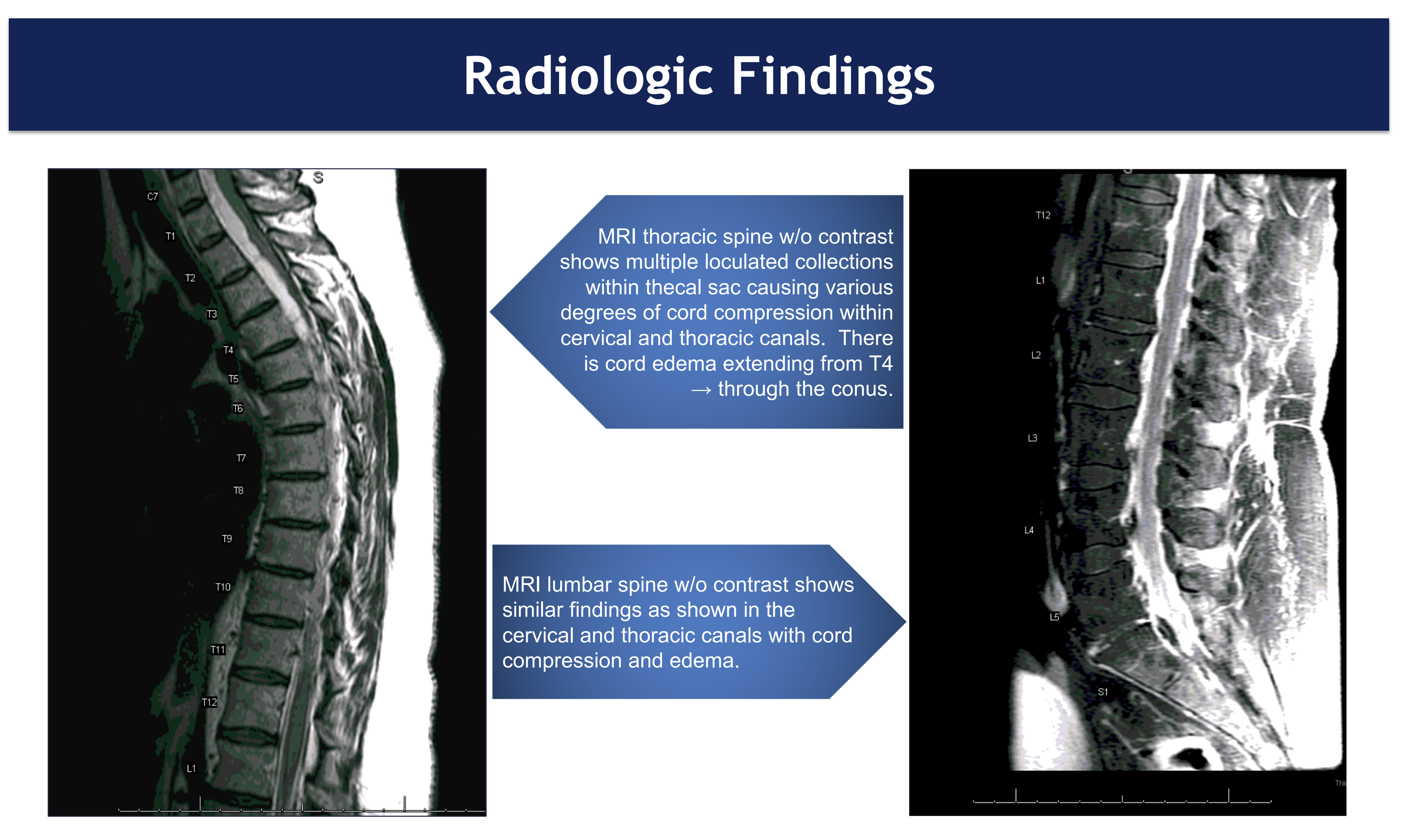

Pathophysiology

- Hemolysis in ruptured aneurysm incites chronic irritation of leptomeninges.

- Inflammatory reaction in the intrathecal compartment may lead to arachnoiditis.

- Nerve root injury and spinal syrinx can subsequently develop.

- Chronic inflammation leading to arachnoid cysts in pia-arachnoid space and fibrotic SA have been widely described in literature.

- Increase in procollagen propeptides in the CSF after SAH has been demonstrated in a time-dependent manner, suggestive of fibroproliferative reaction. ${ }^{11}$

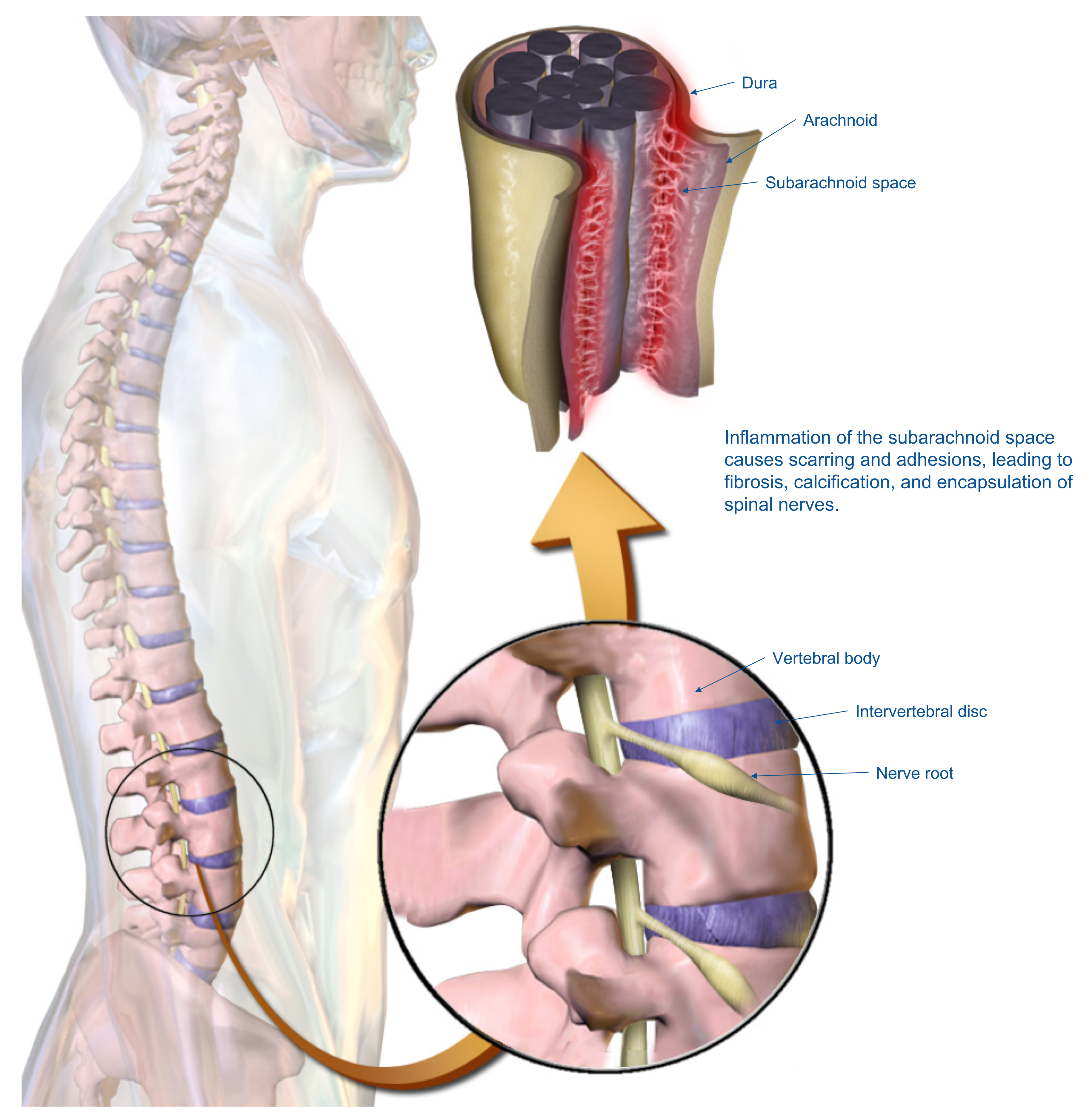

Discussion

\section{Our unique case presentation:}

- Patient developed SA with extensive, multiple localizations, involving segments from the posterior fossa, extending from cervical area to the sacrum.

- One other case had comparable diffuse arachnoiditis of thoracic and lumbar spine 9

- Involvement of cervicomedullary junction, the highest-involved region currently reported in literature. Previously reported highest-involved region was C2.10

Unique symptoms of ataxia, nausea, and vomiting.

- First reported SA from a ruptured VA aneurysm.

- Re-rupture of aneurysm complication.

- Polymicrobial ventriculitis and encephalomalacia in the left and right PICA territories - Unclear if these complications contributed to development of diffuse, severe SA

- Emphasis of potential inflammatory role succeeding SAH and leading to SA development, highlighting the need for closer surveillance of patients with posterior fossa/circulation SAH."

\section{Conclusions}

Clinical course of SA after SAH can be complicated and is the cause of major morbidity Patents SAH. There may be an aneurysis. Choich determine degree of inflammation and subsequent risk of $\mathrm{SA}$.

\section{References}

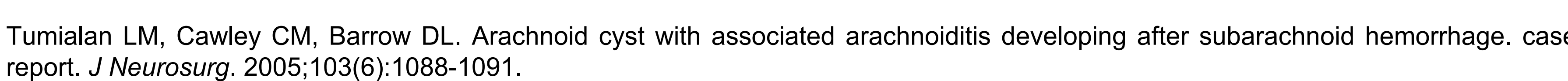
Ishizaka S, Hayashi K, Otsuka M, et al. Syringomyelia and
hemorrhage. Neurol Med Chir (Tokyo). $2012 ; 5299) 686-690$.

Ginanneschi FF, Palma L, Rossi A. Arachnoid cyst and arachnoiditis following idiopathic spinal subarachnoid haemorrhage. Br $\mathrm{J}$
Neurrosurg, 2008;22(4):578-579.

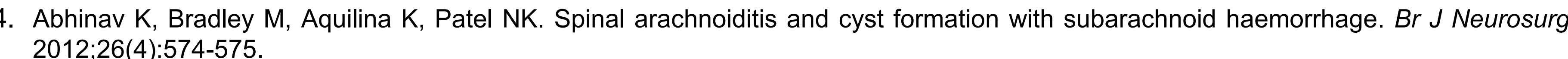

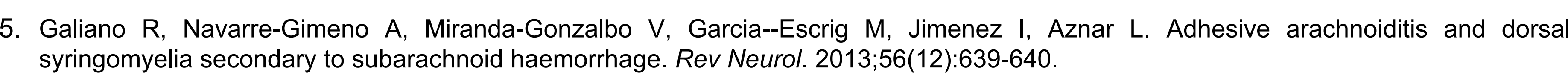

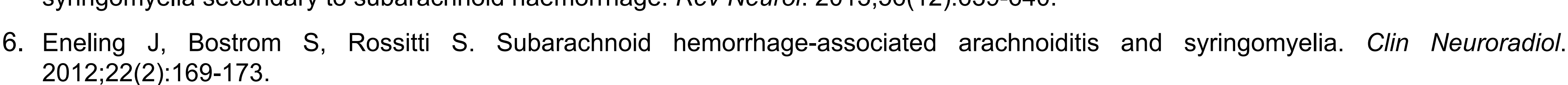

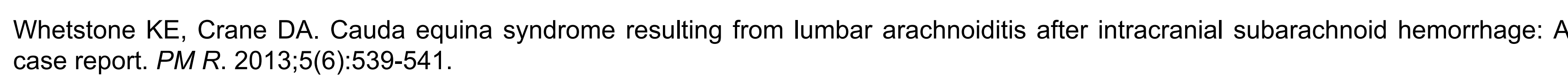

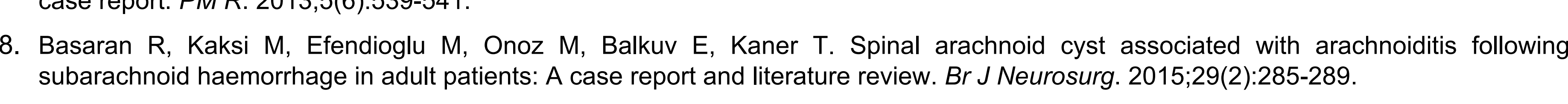
9. van Heerden J, McAulfife W. Spinal arachnoiditis as a consequence of aneurrsm-related subarachnoid haemorrhage. J Med Imaging
Radiat Oncol. 2013:57(1):61-64. Tindra JJ, Varma TR, Weeks RD. Spinal arachnoiditis following subarachnoid haemorrhage. Aust $N Z J$ J Surg. 1989:59(1):84-87.

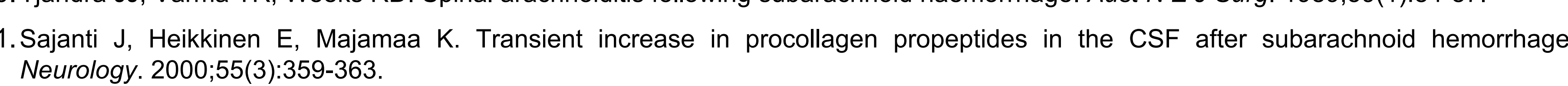

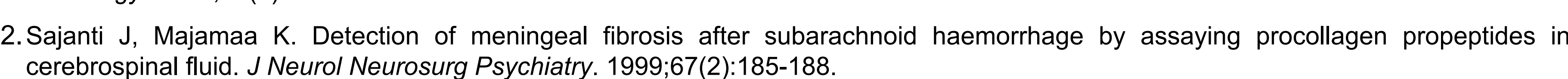
Images: Blausen.-oom staff (2014). "Medical gallery of Blausen Medical 2014". Wikijournal of Medicine 1 (2). Dol:10.15347/wimm2014.010.
ISSN 2002-436

Acknowledgements

Thank you to Dr. Elias Atallah and the Department of Neurosurgery at Thomas Jefferson University Hospital for providing this
research and learning opportunity. Poster made by Sophia Dang 